\title{
Levantamento dos estudos com a própolis produzida no estado da Bahia
}

\author{
Aline Silva Costa ${ }^{1 *}$, Bruna Aparecida Souza Machado ${ }^{1}$, Marcelo Andres Umsza-Guez ${ }^{2}$, Marina Gonçalves \\ Cirqueira $^{1}$, Silmar Baptista Nunes ${ }^{1} \&$ Francine Ferreira Padilha ${ }^{3}$
}

${ }^{1}$ Serviço Nacional de Aprendizagem Industrial, Salvador, Bahia, Brasil.

${ }^{2}$ Universidade Federal da Bahia, Salvador, Bahia, Brasil.

${ }^{3}$ Universidade Tiradentes, Aracaju, Sergipe, Brasil.

\begin{abstract}
Resumo - Própolis é um material de consistência e coloração variada, elaborado por abelhas, a partir de matéria-prima coletada de diversas partes da plantas. Possui uma composição química complexa, a qual depende da flora da região; assim, existem vários tipos de própolis, sendo difícil compará-las. Neste trabalho, é apresentado um levantamento dos estudos realizados com a própolis produzida no estado da Bahia. Foram identificados 17 trabalhos científicos e oito documentos de patentes que tratam da própolis baiana, e elencados três tipos de própolis, dentre as 13 relatadas no Brasil. A maioria dos estudos relatam o potencial da atividade antimicrobiana da própolis do tipo 6 , destacando-se seu baixo teor de flavonoides. Verificou-se também o incentivo que está sendo dado à produção da própolis tipo 13 na Bahia, também denominada de própolis vermelha, devido principalmente ao grande valor agregado a este produto.
\end{abstract}

Palavras-chave adicionais: atividade antimicrobiana, apicultura, documentos de patentes.

\begin{abstract}
Survey of studies with propolis produced in the state of Bahia, Brazil) - Propolis is a product of varied consistency and colour, produced by bees from materials collected from various parts of the plants. It has a complex chemical composition, which depends on the regional flora. Therefore, there are various types of propolis, making comparison between them a difficult task. In the present study, a survey of studies with propolis from the state of Bahia, Brazil, was carried out. We identified 17 scientific papers and eight patents dealing with propolis produced in Bahia. In these works three amongst the 13 types of propolis reported in Brazil were listed. Almost all studies report the antimicrobial activity potential of propolis types 6 , highlighting its low percentage of flavonoids. It was also noted that the incentive given to the production of propolis type 13 in Bahia, also known as "própolis vermelha", is due to the overall aggregate value of this product.
\end{abstract}

Additional key words: antimicrobial activity, apiculture, patents documentation.

Própolis é o produto oriundo de substâncias resinosas, gomosas e balsâmicas coletadas por abelhas de diversas espécies, como Scaptotrigona aff. postica Latreille, 1807 (Souza et al. 2012), Tetragona clavipes Fabricius, 1804 e Melipona mondury Smith, 1863 (Freitas et al. 2012), Tetragonisca angustula angustula Latreille, 1811 e Trigona recursa Smith, 1863 (Barth 2006) e Apis mellifera Linnaeus, 1758. As fontes de coleta de material são brotos, flores e exudatos de plantas, nos quais são acrescentados secreções salivares, cera e pólen para a elaboração final da própolis (Brasil 2001). As secreções salivares que são acrescentadas aos materiais coletados pelas abelhas contêm a enzima $\beta$-glicosidase, acarretando a hidrólise dos flavonoides glicosilados em flavonoides agliconas (Park et al. 1988; Burdock 1998).

O espectro de voo de uma abelha é bastante extenso - o da Apis mellifera, por exemplo, abrange um raio de cerca de 4 a $5 \mathrm{~km}$ em torno da colmeia - e a composição da própolis é um reflexo direto da flora utilizada pelas abelhas (Adelmann 2005). A cor, sabor, odor, consistência, composição química e atividade biológica da própolis dependem principalmente das espécies vegetais que lhes deram origem e da época do ano em que foram produzidas (Paulino 2004). Dessa maneira, a alteração do pasto apícola e mudanças

\footnotetext{
*Autora para correspondência: alinesc@fieb.org.br

Editor responsável: Ricardo Landim Bormann de Borges

Submetido: 3 maio 2013; aceito: 11 nov. 2013

Publicação inicial: 30 dez. 2013; versão final: 2 maio 2014
}

climáticas podem afetar a composição química da própolis, dificultando sua padronização para comercialização. A variação sazonal, por exemplo, pode implicar a diminuição de alguns componentes biologicamente ativos e o aumento de outros (Nunes et al. 2009).

As abelhas utilizam a própolis para vedar frestas e diminuir o tamanho da entrada da colmeia, reduzindo o ataque de intrusos e protegendo a colmeia e suas crias do frio. Serve ainda como material antisséptico, sendo depositada no interior dos alvéolos onde a abelha rainha realiza a postura dos ovos e também é utilizada para envolver inimigos abatidos no interior da colmeia, evitando que apodreçam e contaminem o ninho (Breyer 1982). Segundo Teixeira et al. (2005), não são conhecidos os fatores que direcionam a preferência das abelhas coletoras de resina por uma determinada fonte botânica, mas sabe-se que elas são seletivas nesta coleta.

Dentre as várias formas de utilização de produtos naturais na medicina, destacam-se as plantas brutas, como ervas, além das tradicionais preparações galênicas, como os extratos (Pereira et al. 2002). A própolis é utilizada como complemento alimentar e medicamento. As propriedades biológicas e terapêuticas da própolis têm sido reconhecidas e comprovadas: atividade antimicrobiana (Bittencourt 2008), anti-inflamatória (Moura et al. 2009), cicatrizante (Souza et al. 2009), antiulcerogênica (Barros et al. 2008), antiparasitária (Pontin et al. 2008) e antioxidante (Oldoni et al. 2011). 
São descritas distintas propriedades biológicas e composições químicas para as amostras de própolis coletadas no Brasil, o que é explicado pela grande biodiversidade brasileira (Pereira et al. 2002). Diante da importância econômica e científica aplicada à própolis nos últimos anos, este trabalho teve como objetivo principal caracterizar a própolis produzida no estado da Bahia sob os aspectos físico-químicos, as atividades biológicas e aplicações, a partir do levantamento de trabalhos publicados em bases de dados de artigos científicos e patentes. Foi realizada uma pesquisa nas bases de dados científicos, como Science Direct, Wiley Online Library, SciELO (Scientific Electronic Library Online), e base de dados de documentos de patentes, como a do Instituto Nacional de Propriedade Industrial (INPI), que compila o acervo de todos os documentos de patente de invenção e modelo de utilidade depositados no Brasil. Para o levantamento dos principais trabalhos publicados na área de interesse, utilizou-se uma combinação de palavras-chave, a saber: 'própolis Bahia', 'própolis grupo 6', 'própolis grupo 7' e 'própolis grupo 12', não havendo limite cronológico, sendo selecionados todos os trabalhos identificados que utilizaram própolis oriunda da Bahia.

\section{PróPOLIS NO BRASIL}

Comercialmente, a própolis tem ocupado lugar de destaque no mercado nacional e internacional de produtos apícolas. Tal inserção deve-se essencialmente à constatação das diferentes atividades biológicas atribuídas aos constituintes químicos desse produto (Teixeira et al. 2003). O Brasil é um dos principais produtores mundiais de própolis, com uma produção estimada em torno de 50 a 150 toneladas por ano, sendo que cerca de $75 \%$ desse total é exportado, especialmente para o Japão (97\% das exportações) (Lima 2008). No Brasil, já são mais de 10.000 produtores desse produto apícola, sendo mais de 4.000 produtores da própolis verde, exportando anualmente em torno de US\$ $30.000 .000,00$ do produto na forma de extrato alcoólico ou aquoso, encapsulado, associado a outros vegetais também antioxidantes ou simplesmente na forma bruta (Nascimento Junior 2007). Em julho/2010, por exemplo, as exportações de própolis geraram uma receita de US\$ 46.417,00 (SEBRAE 2010).

A própolis é utilizada na veterinária para cicatrizar de feridas, em cortes pós-operatórios, controle de hemorragias e tratamento de mastite. Na agricultura, ela é aplicada no tratamento de doenças de algumas espécies vegetais, substituindo produtos químicos, enquanto na indústria de cosméticos, é utilizada como constituinte de cremes de beleza, pasta dental, shampoos e sabonetes. Na indústria de alimentos, é um ingrediente funcional de pastilhas, bombons e chicletes
(Costa \& Oliveira 2005). No Brasil, uma enorme quantidade de marcas e produtos feitos à base de própolis encontra-se disponível em lojas de produtos naturais, tais como balas, chocolates, doces, chá, protetor solar, gel pós-barba, shampoos, cremes para pele, soluções antissépticas, pastas de dente, sabonetes, batom, cápsulas, extratos, spray bucal, pastilhas, xaropes, comprimidos etc. (Park \& Ikegaki 1998; Lengler 2012).

A própolis é considerada uma das misturas mais heterogêneas encontradas em fontes naturais; mais de 300 constituintes já foram identificados e/ou caracterizados em diferentes amostras (Lima 2006; Sousa et al. 2007; Lustosa et al. 2008). Dadas às dimensões continentais do Brasil e a grande diversidade da flora e variedade de ecossistemas, sua composição química é extremamente complexa e são vários os tipos de própolis produzidos no país (Lima 2006). Ela pode ser produzida no Brasil todo, porém a qualidade varia de uma região para outra em função de fatores ambientais.

Park et al. (2000) classificaram as amostras de própolis coletadas em todas as Regiões do país (exceto Região Norte) em 12 grupos, de acordo com a aparência e coloração dos extratos (Tabela 1). Posteriormente, foi encontrada uma nova própolis em colmeias localizadas ao longo do litoral e manguezais no nordeste brasileiro, classificada como própolis do grupo 13, denominada própolis vermelha. Observou-se que abelhas coletavam o exsudato vermelho da superfície de Dalbergia ecastophyllum (L.) Taub. (Fabaceae), sugerindo que essa seja a origem botânica da própolis vermelha (Daugsch et al. 2006) e análises cromatográficas verificaram que as amostras de própolis e os exudatos resinosos vermelhos apresentam perfis muito semelhantes em relação ao teor de flavonoides (Daugsch et al. 2008).

\section{PRÓPOLIS DA BAHIA}

Já está definido na literatura (Park \& Ikegaki 1998; Park et al. 2000; Paulino 2004; Adelmann 2005) que a composição química da própolis depende principalmente da flora da região, uma vez que as abelhas coletam o material resinoso das plantas que circundam a colmeia para a produção da própolis. Essa é a principal justificativa para a grande diversidade e quantidade de estudos com diferentes amostras desse material. No presente levantamento bibliográfico foram encontrados 17 trabalhos e oito documentos de patentes que elencam a própolis produzida na Bahia, com a detecção de três tipos de própolis: tipo 6 (marrom-avermelhada), tipo 7 (marrom-esverdeada) e tipo 13 (vermelha).

Segundo os trabalhos de Park et al. (2000) e Alencar (2002), nos quais a própolis brasileira foi classificada em 12 grupos, as amostras da Bahia 
Tabela 1. Agrupamento da própolis brasileira quanto à cor. Local de coleta: RS- Rio Grande do Sul; PR- Paraná; BA- Bahia; PEPernambuco; CE- Ceará; PI- Piauí; SP- São Paulo). Fonte: Park et al. (2000).

\begin{tabular}{|c|c|c|c|}
\hline \multicolumn{4}{|c|}{ Extrato Etanólico de Própolis } \\
\hline Grupos* & Cor & Substâncias Solúveis (\%) & Origem da própolis \\
\hline Grupo 1 (RS) & Amarelo & 63,0 & Região Sul \\
\hline Grupo 2 (RS) & Castanho Claro & 57,0 & Região Sul \\
\hline Grupo 3 (PR) & Castanho Escuro & 65,0 & Região Sul \\
\hline Grupo 4 (PR) & Castanho Claro & 54,5 & Região Sul \\
\hline Grupo 5 (PR) & Marrom esverdeado & 58,7 & Região Sul \\
\hline Grupo 6 (BA) & Marrom avermelhado & 45,9 & Região Nordeste \\
\hline Grupo 7 (BA) & Marrom esverdeado & 43,8 & Região Nordeste \\
\hline Grupo 8 (PE) & Castanho Escuro & 41,3 & Região Nordeste \\
\hline Grupo 9 (PE) & Amarelo & 46,7 & Região Nordeste \\
\hline Grupo $10(\mathrm{CE})$ & Amarelo Escuro & 24,1 & Região Nordeste \\
\hline Grupo $11(\mathrm{PI})$ & Amarelo & 23,1 & Região Nordeste \\
\hline Grupo 12 (SP) & Verde ou marrom esverdeado & 61,0 & Região Sudeste \\
\hline
\end{tabular}

(grupos 6 e 7) foram coletadas nas cidades de Anagé, Barra da Choça, Entre Rios, Jacobina, Juazeiro, Remanso, Salvador, Senhor do Bonfim e Vitória da Conquista, não o grupo de própolis produzido em cada cidade. Nesses estudos, a própolis do tipo 6 se destacou por ter apresentado um perfil fotoquímico não encontrado nas outras própolis estudadas. Além disso, notou-se também um grande incentivo do governo estadual para aumentar a produção da própolis vermelha, principalmente na região Sul da Bahia, onde se concentra uma grande área de manguezais, locais bastante favoráveis para a coleta de resina para a produção da própolis vermelha. A atual produção dessa própolis ainda é considerada pequena, apenas $200 \mathrm{~kg}$ por ano sendo esse incentivo justificado pelo grande valor agregado à própolis vermelha, que pode ser vendida por até R\$ 450,00 o kg (SECOM 2011).

Korn et al. (2013) avaliaram traços de elementos minerais em 48 amostras de própolis coletadas em diferentes regiões da Bahia (Chapada Diamantina, Litoral Norte, Oeste, Recôncavo, Sudoeste e Sul). Foi verificado que havia diferenças nos teores encontrados para alguns elementos, a saber, $\mathrm{Na}, \mathrm{Ba}, \mathrm{Ca}, \mathrm{Cu}, \mathrm{Fe}, \mathrm{K}$, Mg, Mn, Ni e Zn. Através da Análise de Componentes Principais (PCA) foi evidenciada a formação de três grupos (A, B e C). O grupo A reuniu amostras relativas à própolis da região da Chapada Diamantina, enquanto os grupos $\mathrm{B}$ e $\mathrm{C}$, de localidades próximas (Litoral Norte) e distantes do litoral, respectivamente. Foi observado que os elementos $\mathrm{Ni}, \mathrm{Zn}$ e $\mathrm{K}$ foram mais influentes na separação do grupo $\mathrm{A}$, enquanto $\mathrm{Ba}$ foi importante para o grupo $\mathrm{B}$ e os elementos $\mathrm{Cu}, \mathrm{Fe}, \mathrm{Mg}$ e Mn para a discriminação do grupo C. Os valores mais sifnigicativos foram o de magnésio e de ferro, superiores nas amostras coletadas do Litoral Norte.

Os diversos estudos feitos com própolis da Bahia concentram-se naquela do tipo 6, com o intuito principal de se verificar a atividade antimicrobiana.
Esse tipo de própolis ganhou destaque na área científica depois que diversas pesquisas encontraram um perfil fitoquímico diferenciado, principalmente em relação ao teor de flavonoides (Koo et al. 2000; Moura 2000; Alencar 2002; Duarte 2002). Koo et al. (2000) demonstraram características bastante particulares desta própolis, como alta atividade antimicrobiana e composição química caracterizada por componentes apolares e ausência de flavonoides anglicanas. Os flavonoides são considerados os principais compostos responsáveis pelos efeitos benéficos da própolis. Esses compostos fenólicos provenientes de plantas agem em diferentes processos fisiológicos e exercem função antimicrobiana e antioxidante (Barbosa et al. 2009).

Há grande controvérsia em relação ao verdadeiro teor de flavonoides nas amostras de própolis do Brasil (Pereira et al. 2002). Estudos realizados por Bankova et al. (1995) e Sousa et al. (2007) concluíram que as amostras de própolis brasileira apresentaram baixos teores de flavonoides totais e ésteres de ácidos fenólicos, possuindo altas concentrações de ácido dihidroxicinâmico, acetofenonas preniladas e alguns terpenoides específicos. Como consequência destas diferenças na composição química da própolis, é observada também uma variação nas suas propriedades farmacológicas (Menezes 2005), tendo em vista principalmente o teor dos compostos bioativos presentes nas amostras. Diante de tal diferença, foi criada a Instrução Normativa $n^{\circ} 3$, de 19 de janeiro de 2001 para regulamentar o produto apícola que, nos anexos VI e VII de sua resolução, determina os padrões para fixação de identidade e qualidade de própolis e regulamenta a identidade e qualidade de extratos de própolis proveniente da extração dos componentes solúveis em álcool neutro (Brasil 2001). É determinado que estes produtos devam possuir teor mínimo de flavonoides de $0,5 \%(\mathrm{~m} / \mathrm{m})$ e $0,25 \%(\mathrm{~m} / \mathrm{m})$ para própolis e extrato de própolis, respectivamente. 
Um estudo bastante amplo em relação aos aspectos físico-químicos e biológicos das própolis produzidas pela abelha Apis mellifera na Região Nordeste do Brasil foi realizado por Moura (2000). Das 12 amostras estudadas, nove eram provenientes do estado da Bahia. Mais uma vez, foi observado que uma das amostras da Bahia, mais especificamente da Mata Atlântica e do tipo 6 (coletadas na cidade de Salvador e Entre Rios), apresentava um perfil cromatográfico não encontrado em nenhuma própolis brasileira estudada até então, possuindo compostos de características mais apolares que as demais própolis e apresentando uma excelente atividade antimicrobiana, verificada através da formação do halo de inibição contra Staphylococcus aureus e Streptococcus mutans. Foi encontrado um teor de flavonoides totais entre as amostras baianas variando de 4,36 a 26,44 $\mathrm{mg} \mathrm{g}^{-1}$ de própolis. Moura (2000) salientou que a própolis da Bahia com maior atividade antimicrobiana apresentou o menor teor de flavonoides indicando que, possivelmente, a atividade antimicrobiana desse produto não se deve aos flavonoides. Cabral et al. (2012) estudou a própolis do tipo 6 obtida na Mata Atlântica da cidade de Entre Rios (BA) e encontrou teor de fenólicos de $1,48 \%$ e teor de flavonoide de $0,32 \%$, considerado baixo em relação às outras própolis estudadas por eles. Apesar deste baixo teor, esta propolis também apresentou alta atividade microbiana.

Alencar et al. (2001) investigaram quimicamente própolis da região da Mata Atlântica, coletadas na cidade de Entre Rios (Bahia) e folhas de Hyptis divaricata Pohl ex Benth. (Lamiaceae), espécie mencionada como sua fonte botânica, mediante o uso das técnicas de cromatografia em camada delgada de alta eficiência - fase reversa (CCDAE-FR), cromatografia líquida de alta eficiência - fase reversa (CLAE-FR) e cromatografia em fase gasosa acoplada a espectrometria de massa (CG-EM). Eles concluíram que a composição dos compostos fenólicos encontrados na própolis na Mata Atlântica da Bahia possibilitou uma clara diferenciação dos outros grupos de própolis encontrados no Brasil. Além disso, a origem botânica desse tipo de própolis mostrou ser a espécie vegetal $H$. divaricata. Foi também avaliada, através de antibiograma, a própolis coletada em diferentes estações do ano, quanto à atividade antibacteriana contra Staphylococcus aureus, demonstrando que, qualitativamente, as amostras de própolis coletadas ao longo do ano demonstraram alta atividade antimicrobiana, o que poderia estar relacionado principalmente às benzofenonas isopreniladas. As benzofenonas são compostos fenólicos que apresentam alta atividade antimicrobiana, antitumoral e antioxidante, e estão entre os compostos químicos mais importantes identificados e isolados a partir de própolis encontradas em regiões tropicais, incluindo por exemplo, o estado da Bahia.
Comprovando mais uma vez o potencial antimicrobiano da própolis tipo 6 (Bahia), Duarte (2002) estudou o extrato etanólico da própolis bruta (EEP), que se comportou como um agente antimicrobiano bastante promissor, inibindo o crescimento de Streptococcus mutans em baixas concentrações, sendo bactericida para a maioria dos microrganismos testados, além de ser capaz de inibir cepas de coleção e também microrganismos isolados recentemente de pacientes. Este trabalho demonstrou que a própolis tipo 6 pode ter um efeito biológico in vivo na prevenção da placa dental cariogênica e cárie dental. Além disso, o estudo deixou claro que os compostos biologicamente ativos desta própolis têm características apolares, como apontado por outros autores, sendo encontrados tanto na fração hexana quanto na clorofórmica, mostrando-se importante o isolamento e a identificação destes compostos, assim como a análise de seus possíveis mecanismos de ação.

No estudo realizado por Castro et al. (2009a), foi verificado o perfil cromatográfico da própolis tipo 6 e foi possível identificar a benzofenona prenilada como um dos principais compostos. Castro et al. (2009b) também avaliaram a própolis do tipo 6 (Mata Atlântica

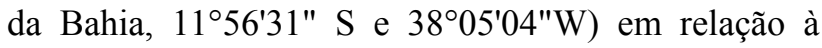
concentração inibitória mínima (MIC) e à mínima concentração bactericida (MBC) dos extratos etanólicos e suas frações e subfrações orgânicas. No estudo, foram determinados valores de MIC que indicavam que a fração hexana exibia forte atividade antibacteriana contra Staphylococcus aureus e Streptococcus mutans, com concentrações tão baixas como 25 e $50 \mu \mathrm{g} \mathrm{mL} \mathrm{m}^{-1}$, respectivamente, indicando a presença de um composto ativo nessa fração, possivelmente benzofenona, de acordo com a análise cromatográfica realizada. Valores semelhantes de MIC foram determinados por Daugsch (2007), que também avaliou a própolis tipo 6. Castro et al. (2009b) não detectaram flavonoides, nem os derivados de ácido cinâmico em amostras dessa própolis, o que foi confirmado através das análises por CLAE, CG-EM e HRGC-FID (cromatografia gasosa de alta eficiênciadetector de ionização de chamas).

Outro estudo com a propolis tipo 6 da Bahia teve como objetivo avaliar seu efeito na mastite subclínica (Costa et al. 2011). Entretanto, nas concentrações testadas, não houve efeito positivo desta própolis como agente para o tratamento da patologia durante os dias avaliados (72 h). Já Simões (2008) avaliou a ação antimicrobiana de extratos comercias de própolis frente aos microrganismos presentes na saliva total e estimulada de humanos, entre os extratos comerciais utilizados, um era oriundo da Bahia (própolis do tipo 6). A análise dos resultados indicou que os extratos comerciais possuem ação antimicrobiana contra os patógenos bucais, assim como constatado em análise in vitro. 
Righi (2008) estudou o teor de compostos fenólicos totais (\%), flavonoides totais (\%) e ceras (\%) em própolis produzida na região de Cabo Verde (Bahia), verificando teores de 25,87 para compostos fenólicos, 3,15 para flavonoides e 22,59 para ceras. A porcentagem de compostos fenólicos e flavonoides obtida foi a terceira maior dentre as nove amostras avaliadas pelo autor, ficando atrás apenas da própolis produzida na região de Pirenópolis (Goiás) e em Maceió (Alagoas). Foi identificado também que os derivados de ácido cafeoilquínicos e fenilpropanóides prenilados e muitas flavonas glicosiladas estavam presentes nas amostras, como luteolina-o-rutinosídeo, chaftosídeo, crisoeriol-o-glicosídeo, isochaftosídeo e apigenina-di-o-glicosídeo, além de flavonóis glicosilados, como quercetina o-ramnosídeo e rutina, e, ainda, uma flavanona glicosilada (dimetoxi naringenina-di-C-glicosídeo).

A provável fonte vegetal comparada com a análise da composição química é o melhor indicador da origem botânica da própolis (Alencar et al. 2005). A análise polínica das amostras de própolis é uma técnica pouco utilizada na pesquisa, já que requer conhecimentos amplos de palinologia (Freitas 2002). A palinologia, que designa o estudo morfológico do grão de pólen, bem como sua dispersão e aplicações, teve início no século XVII, quando se desenvolveu a microscopia ótica, permitindo que estas partes diminutas das plantas pudessem ser observadas com precisão (SalgadoLabouriau 1973). Através da morfologia do grão de pólen é possível a identificação de táxons vegetais, permitindo a inferência sobre a composição da vegetação local e regional através de associações polínicas (Barth et al.1999; Barth \& Luz 2009).

Existem diversas espécies vegetais para a retirada de resina pelas abelhas. Entretanto, poucas são as espécies identificadas até o momento; Vernonanthura phosphorica (Vell.) H.Rob. (assa-peixe; Asteraceae), Schinus terebinthifolius Raddi (aroeira; Anacardiaceae), Baccharis spp. (alecrim; Asteraceae) e Eucaliputus spp. (eucalipto; Myrtaceae) são alguns exemplos de espécies vegetais onde as abelhas buscam matéria-prima para a produção da própolis (Park et al. 2000). Barth \& Luz (2009) em um estudo palinológico de amostras de própolis vermelha incluindo três amostras da Bahia coletadas em áreas de manguezais das cidades de Camamu, Mucurí e Prado identificaram a presença principalmente de resina de Schinus, conhecida popularmente como aroeira-pimenteira.

Dentre os oito documentos de patente, seis são de titularidade do Serviço Nacional de Aprendizagem Industrial (Bahia) e relatam o desenvolvimento de bebidas energéticas a base de própolis (PI011110000637, BR102013005726-6, BR102013005729-0, BR1020130057231, BR102013005725-8 e BR102013005727-4); as outras duas patentes (PI0215610-5 e PI0215673-3) são de titularidade de Luciete Santos Ferreira ME, e referemse a complementos alimentares e/ou energéticos que possuem própolis como um dos seus componentes ativos.

\section{CONSIDERAÇões FinaIS}

Neste levantamento, foram encontrados 17 trabalhos e oito documentos de patentes que relatam a produção de três tipos de própolis na Bahia, dentre as 13 encontradas para o Brasil. As própolis do grupos 6 e 13 possuem grande potencial para a indústria de alimentos e farmacêutica devido principalmente às suas características funcionais Os estudos estão concentrados na determinação da atividade antimicrobiana, obtendo resultados positivos e bem expressivos, principalmente para a própolis do tipo 6 , caracterizada pelo baixo teor de flavonoides. A outra própolis de grande importância encontrada na Bahia é a do grupo 13 (vermelha), descoberta recentemente. Sua produção na Bahia ainda é reduzida, mas já existe incentivo do governo para acelerar a produção, principalmente por causa das atividades biológicas já comprovadas para este produto.

\section{REFERÊNCIAS}

Adelman, J. 2005. Própolis: variabilidade composicional, correlação com a flora e bioatividade antimicrobiana/oxidante. Dissertação de Mestrado. Universidade do Paraná.

Alencar, S.M. 2002. Estudo Fitoquímico da Origem Botânica da Própolis e Avaliação da Composição Química de Mel de Apis melifera africanizada de diferentes regiões do Brasil. Tese de Doutorado. Universidade Estadual de Campinas.

Alencar, S.M.; Park, Y.K.; Aguiar, C.L. \& Mariuzzo, D.M. 2001. Evidências fítoquímicas da própolis da região de Mata Atlântica do estado da Bahia. Revista Baiana de Tecnologia 16: $154-160$

Alencar, S.M.; Aguiar, C.L.; Paredes-Guzmán, J. \& Park, Y.K. 2005. Composição química de Baccharis dracunculifolia, fonte botânica das própolis dos estados de São Paulo e Minas Gerais. Ciência Rural 25: 909-915.

Bankova, V.; Christov, R.; Kujumgiev, A.; Marcucci, M.C. \& Popov, S. 1995. Chemical composition and antibacterial activity of Brazilian propolis. Zeitschrift für Naturforschung 50: $167-172$

Barbosa, M.H.; Zuffi, F.B.; Maruxo, H.B. \& Jorge, L.L.R. 2009. Ação terapêutica da própolis em lesões cutâneas. Acta Paulista de Enfermagem 22: 318-22.

Barros, M.P.; Lemos, M.; Maistro, E.L.; Leite, M.F.; Sousa, J.P.; Bastos, J.K. \& Andrade, S.F. 2008. Evaluation of antiulcer activity of the main phenolic acids found in Brazilian green propolis. Journal of Ethnopharmacology 120: 372-377.

Barth, O.M. 2006. Palynological analysis of geopropolis samples obtained from six species of Meliponinae in the Campus of the Universidad de Ribeirão Preto, USP, Brazil. Apiacta 41: 71-85.

Barth, O.M. \& Luz, C.F.P. 2009. Palynological analysis of Brazilian red propolis samples. Journal of Apicultural Research and Bee World 48: 181-188.

Barth, O.M.; Dutra, V.M.L. \& Justo, R.L. 1999. Análise polínica de algumas amostras de própolis do Brasil meridional. Ciência Rural 29: 663-667. 
Bittencourt, F.O. 2008. Desenvolvimento e Avaliação da Atividade Antimicrobiana Contra Candida albicans de Formulações Semisólidas Contendo Própolis Vermelha. Dissertação de Mestrado. Universidade Tiradentes.

Brasil 2001. Departamento de Inspeção de Produtos de Origem Animal. Regulamentos técnicos de identidade e qualidade do mel e produtos apícolas. MAPA/DAS/ DIPOA/DNT, Brasília.

Breyer, E.U. 1982. Abelhas e Saúde. 2 ed. Uniporto Gráfica e Editora Ltda, Paraná.

Burdock, J.S. 1998. Review of the biological properties and toxicity of bee propolis. Food and Chemical Toxicology 36 347-363.

Cabral, I.S.R.; Oldoni, T.L.C.; Alencar, S.M.A.; Rosalen, P.L. \& Ikegaki, M. 2012. The correlation between the phenolic composition and biological activities of two varieties of Brazilian propolis (G6 and G12). Brazilian Journal of Pharmaceutical Sciences 48: 557-564.

Castro, M.L.; Nascimento, A.M.; Ikegaki, M.; Costa-Neto, C.M.; Alencar, S.M. de \& Rosalen, P.L. 2009a. Identification of a bioactive compound isolated from Brazilian propolis type 6. Bioorganic \& Medicinal Chemistry 17: 5332-5335.

Castro, M.L.; Vilela, W.R.; Zauli, R.C.; Ikegaki, M.; Rehder, V.L.G.; Foglio, M.A.; Alencar, S.M. de \& Rosalen, P.L. $2009 \mathrm{~b}$. Bioassay guided purification of the antimicrobial fraction of a Brazilian propolis from Bahia state. $B M C$ Complementary and Alternative Medicine 9: 25-30.

Costa, P.S.C. \& Oliveira, J.S. 2005. Manual Prático de Criação de Abelhas. Editora Aprenda Fácil, Viçosa.

Costa, N.C.; Andrea, M.V.; Carvalho, G.J.L.; Almeida, A.M.L. \& Ledo, C.A.S. 2011. Avaliação do efeito do extrato de própolis no tratamento da mastite subclínica em vacas de leite. Magistra 23: 257-261.

Daugsch, A. 2007. A Própolis Vermelha do Nordeste do Brasil e suas Características Químicas e Biológicas. Tese de Doutorado. Universidade Estadual de Campinas.

Daugsch, A.; Moraes, C.S.; Fort, P.; Pacheco, E.; Lima, I.B.; Abreu, J.A. \& Park, Y.K. 2006. Própolis Vermelha e sua origem botânica. Mensagem Doce. 89. Disponível em http//:www.apacame.org.br; acesso em: 30 set. 2012.

Daugsch, A.; Moraes, C.S.; Fort, P. \& Park, Y.K. 2008. Brazilian red propolis - chemical composition and botanical origin Evidence-Based Complementary and Alternative Medicine 5: 435-441.

Duarte, S. 2002. Estudo In Vitro do Efeito da Própolis da Bahia (Mata Atlântica) Sobre Estreptococos do Grupo mutans e na Atividade das Glucosiltransferases. Dissertação de Mestrado. Faculdade de Odontologia de Piracicaba.

Freitas, A.S.; Vit, P. \& Barth, O.M. 2012. Pollen profile of geopropolis samples collected by native bees (Meliponini) in South American countries. Sociobiology 59: 1-16.

Freitas, F.O. 2002. Uso da palinologia em amostras arqueológicas de própolis na reconstituição da vegetação histórica de uma região. Boletim de Pesquisa e Desenvolvimento 22: 1-17.

Koo, H.; Rosalen, P.L.; Cury, J.A.; Ambrosano, G.M.B.; Murata, R.M.; Yatsuda, R.; Ikegaki, M.; Alencar, S.M. \& Park, Y.K. 2000. Effect of a new variety of Apis mellifera propolis on mutans streptococci. Current Microbiology 41: 192-196.
Korn, M.G.A.; Guida, M.A.B.; Barbosa, J.T.P.; Torres, E.A.; Fernandes, A.P.; Santos, J.C.C.; Dantas, K.G.F.; Nóbrega, J.A. 2013. Evaluation of sample preparation procedures for trace element determination in Brazilian propolis by inductively coupled plasma optical emission spectrometry and their discrimination according to geographic origin. Food analytical methods 6: 872-880.

Lengler, S. 2012. Própolis. Disponível em http:// www.brasilapicola.com.br/node/105; acesso em 3 set 2012

Lima, G. 2008. Estudo sobre Mel, Cera e Própolis. ApexBrasil, Brasília.

Lima, M.G. 2006. A Produção de Própolis no Brasil. São Sebastião Editora e Gráfica, São João da Boa Vista.

Lustosa, S.R.; Galindo, A.B.; Nunes, L.C.C.; Randau, K.P. \& Rolim Neto, P.J. 2008. Própolis: atualizações sobre a química e a farmacologia. Revista Brasileira de Farmacognosia 18: 447454.

Menezes, H. 2005. Própolis: uma revisão dos recentes estudos de suas propriedades farmacológicas. Arquivos do Instituto Biológico 72: 405-411.

Moura, F.F. 2000. Determinação das Propriedades Físicoquímicas e Biológicas da Própolis Produzida por Apis mellifera na Região Nordeste do Brasil. Dissertação de mestrado. Universidade Estadual de Campinas.

Moura, S.A.L.; Negri, G.; Salatino, A.; Lima, L.D.C.; Dourado, L.P.A.; Mendes, J.B.; Andrade, S.P.; Ferreira, M.A.N.D. \& Cara, D.C. 2009. Aqueous extract of Brazilian green propolis: primary components, evaluation of inflammation and wound healing by using subcutaneous implanted sponges. Evidence Based Complementary Alternative Medicine 2011: 1-9.

Nascimento Junior, A.V. 2007. A produção de própolis no Brasil. In: Anais do IV Seminário de Própolis do Nordeste, ilhéus, 24 26 out. 2007, p. 36-43.

Nunes, L.C.C.; Galindo, A.B.; Deus，A.S.O.; Rufino，D.A.; Randau, K.P.; Xavier, H.S.; Citó, A.M.G.L. \& Rolim Neto, P.J. 2009. Variabilidade sazonal dos constituintes da própolis vermelha em bioatividade em Artermia salina. Revista Brasileira de Farmacognosia 19: 524-529.

Oldoni, T.L.C.; Cabral, I.C.R.; D'Arcea, M.A.B.R.; Rosalen, P.L.; Ikegaki, M.; Nascimento, A.M. \& Alencar, S.M. 2011. Isolation and analysis of bioactive isoflavonoids and chalcone from a new type of Brazilian propolis. Separation and Purification Technology 77: 208-213.

Park, Y.K. \& Ikegaki, M. 1998. Preparation of water and ethanolic extracts of propolis and evaluation of the preparations. Bioscience, Biotechnology, and Biochemistry 62: 2230-2232.

Park, Y.K.; Ikegaki, M.; Abreu, J.A.S. \& Alcici, N.M.F. 1988. Estudo da preparação dos extratos de própolis e suas aplicações. Revista Ciência e Tecnologia de Alimentos 18: 313-318.

Park, Y.K.; Ikegaki, M. \& Alencar, S.M. 2000. Classificação das própolis brasileira a partir de suas características físicoquímicas e propriedades biológicas. Mensagem Doce 58. Disponível em http//:www.apacame.org.br; acesso em 3 set. 2012.

Paulino, F.D.G. 2004. Produtos da colmeia. In: D.C. Souza, (ed.), Apicultura: manual do agente de desenvolvimento rural. SEBRAE, Brasília. 
Pereira, A.S.; Seixas, F.R.M.S. \& Neto, F.R.A. 2002. Própolis: 100 anos de pesquisa e suas respectivas futuras. Química Nova 25: $321-326$.

Pontin, K.; Silva Filho, A.A.; Santos, F.F.; Silva, M.L.; Cunha, W.R.; Nanayakkara, N.P.; Bastos, J.K. \& Albuquerque, S. 2008. In vitro and in vivo antileishmanial activities of a Brazilian green propolis extract. Parasitology Research 103: $487-492$.

Righi, A.A. 2008. Perfil Químico de Amostras de Propólis Brasileiras. Dissertação de Mestrado. Universidade São Paulo.

Salgado-Labouriau, M.L. 1973. Contribuição à Palinologia dos Cerrados. Academia Brasileira de Ciências, Rio de Janeiro.

SECOM (Secretaria de Comunixação Social) 2011. EBDA estimula produção de própolis vermelha no sul do estado. Notícias Agricultura, 11 ago. 2011. Disponível em http://www. comunicacao.ba.gov.br/noticias/2011/08/11/ebda-estimulaproducao-de-propolis-vermelha-no-sul-do-estado; acesso em: 1 out. 2012.

SEBRAE (Serviço Brasileiro de Apoio às Micro e Pequenas empresas) 2010. Exportação Brasileira de Cera de Abelha (Própolis). Disponível em http://www.sebrae.com.br/setor/ apicultura/sobre/apicultura/mercado/exportacoes/Exportacoes\% 20Julho.pdf; acesso em 14 ago. 2012.
Simões, C.C.; Araújo, D.B. \& Araújo, R.P.C. 2008. Estudo in vitro e ex vivo da ação de diferentes concentrações de extratos de própolis frente aos microrganismos presentes na saliva de humanos. Revista Brasileira de Farmacognosia 18: 84-89.

Sousa, J.P.B.; Furtado, N.A.J.C.; Jorge, R.; Soares, A.E.E. \& Bastos, J.K. 2007. Perfis físico-químico e cromatográfico de amostras de própolis produzidas nas microrregiões de Franca (SP) e Passos (MG), Brasil. Revista Brasileira de Farmacognosia 17: 85-93.

Souza, A.P.B.; Passos, J.P.G.; Padilha, A.F.F.; Albuquerque Júnior, R.L.C. \& Cardoso, J.C. 2009. Efetividade da Delphinum staphysagria $6 \mathrm{cH}$ e $30 \mathrm{cH}$ em ensaios biológicos para cicatrização. Brazilian Homeopathic Journal 11: 13-14.

Souza, H.R.; Pando, A.M.S.C.; Cruz-Barros, M.A.V. \& Albuquerque, P.M.C. 2012. Espectro polínico da própolis da abelha sem ferrão Tubi - Scaptotrigona aff. postica Latreille, 1807 (Hymenoptera: Apidae: Meliponini) em Barra do Corda MA - Brasil. In: 19a Reunião Anual do Instituto de Botânica, São Paulo, 2012.

Teixeira, E.W.; Message, D.; Meira, R.M.A. \& Salatino, A. 2003. Indicadores da origem botânica da própolis: importância e perspectivas. Boletim de Indústria Animal 60: 83-106.

Teixeira, E.W.; Negri, G.; Meira, R.M.; Message, D. \& Salatino, A. 2005. Plant origin of green propolis: bee behavior, plant anatomy and chemistry. Evidence-based Complementary and Alternative Medicine 2: 85-92. 